\title{
Stories Notebook about the Fundamental Concepts in Family Medicine: Context and Contextualization, the Fable of The Buffaloes and The Bison
}

\author{
Jose Luis Turabian *
}

Health Center Santa Maria de Benquerencia Toledo, Spain

"Corresponding author: Jose Luis Turabian, Health Center Santa Maria de Benquerencia Toledo, Spain, Tel: 34925154508; Email: jturabianf@hotmail.com

Received date: March 31, 2017; Accepted date: April 17, 2017; Published date: April 25, 2017

Copyright: () 2017 Turbian JL. This is an open access article distributed under the terms of the Creative Commons Attribution License, which permits unrestricted use, distribution, and reproduction in any medium, provided the original author and source are credited.

\section{Introduction}

In this section of Stories Notebook about the Fundamental Concepts in Family Medicine, you will learn the fundamental concepts of General Medicine/Family Medicine through stories or fables.

Conceptual systematization in the specialty of Family Medicine/ General Medicine has not matched with practice. However, it is not until that the conceptual heritage of Family Medicine, is ordered, systematized and fully clarified when it can begin the real practical work [1].

Therefore, it is necessary to achieve more meaningful representations of the fundamental concepts of Family Medicine, and facilitate the transfer of these to clinical practice. But, these concepts can be difficult to understand and explain, even for experienced physicians in the specialty. Thus, we propose the following concepts of Family Medicine/General Medicine, which we think are the main:

1. Comprehensiveness and integrality

2. Continuity

3. Context and contextualization

4. Uncertainty

5. Complexity

6. Community

7. Patient-centered interview

8. Biopsicosocial model

9. Actors and resources/strengths of the patients

10. Medicalization and technology

11. Family

12. Symptoms

13. Diagnosis and treatment

14. Concept of health and disease; and

15. Variability

Evidence-Based Medicine, clinical trials and quantitative studies are necessary, indispensable for medical science, yes, but why not the stories, the tales and the cases? So, we will be presented these concepts by fables [2-5].

The fable is an adult education method that can serve to intuitively understand abstract concepts by linking them to specific situations, for facilitating their assimilation. Animals, plants, minerals and other things will be "patients" seen in consultation by the family doctor.
They will be fictional stories presented as real. They will be beings or objects that are given the opportunity to think, feel and speak. In the fable it can be distinguished two parts: one is the story itself; and the other moral. Each story seeks to make emerge, of clear form, the moral, the end of the fable, as sobering consequence of what happened in the episode [6,7]. The moral will be a fundamental concept of Family Medicine/General Medicine.

\section{Short Communication}

Once upon a time that the Wild Buffalo of Asia consulted with his family doctor. He had uncomplicated angina pectoris and cluster headache.

"Which drug is most effective in the treatment of uncomplicated angina pectoris? And, which drug is most effective in the treatment of cluster headache?", the doctor asked himself". This is a relatively easy to treat problem. I just have to look at the protocols (evidence-based medicine) available", told himself the doctor.

Later in the consultation the Mr. African Buffalo appeared, also presenting uncomplicated angina pectoris and cluster headache.

"What is the most cost-effective treatment for the angina pectoris? And, what is the most cost-effective treatment for cluster headaches?" the doctor asked himself. "It's a more complicated question to answer than that of the Mr. Wild Buffalo of Asia, but I can get to know it through Quantitative Research Protocols", told himself the doctor [8]. Later the Mr. American Bison appeared in the consultation.

After the interview and exploration, the family physician had to decide how to treat a low-social-status patient with angina pectoris, cluster headache, depression, and alcohol abuse, which also presents legal, economic, and family problems.

"What is the best treatment for a low social level patient, with angina pectoris, cluster headache, depression and alcohol abuse, who also has legal, economic, and family problems?", told himself the doctor. "This is a question even more complex than that of the Mr. Wild Buffalo of Asia, and more so than that of the Mr African Buffalo I will have to use a bio-psycho-social theoretical framework and qualitative tools to management of the query: context, experience, evolution, common sense, strategic planning, emotion and intuition, ethics, patient participation, etc." Finally came to see the Doctor the Mr European Bison who presented drunkenness crisis by excessive consumption of alcohol, with angina pectoris, depression, cluster headache, smoker, with legal, economic, and family problems, religious, with non-compliance, consultant frequent, with an occasional hostile behavior, and living in an isolated rural area $[9,10]$ (Figure 1). 
Citation: Turabian JL (2017) Stories Notebook about the Fundamental Concepts in Family Medicine: Context and Contextualization, the Fable of The Buffaloes and The Bison. J Gen Pract (Los Angel) 5: 304. doi:10.4172/2329-9126.1000304

Page 2 of 2

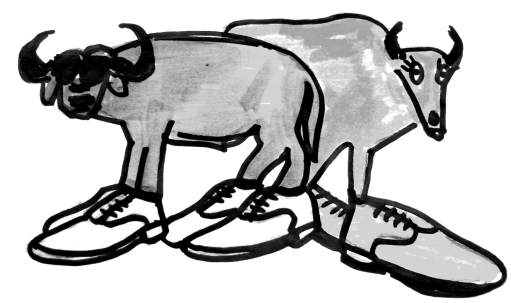

Figure 1: The Fable of The Buffaloes and The Bison.

"What is the best treatment of a patient with a drunken crisis due to excessive alcohol consumption, with angina pectoris, depression, cluster headache, smoker, legal, economic and family problems, religious, noncompliant, and who is a consultant frequent, with an occasional hostile behavior, and living in an isolated rural area?", asked himself the doctor. "This is a chaotic situation, more difficult to answer than that of the Mr Wild Buffalo of Asia, and more than that of the $\mathrm{Mr}$ African Buffalo, and more than that of Mr North American Bison. I will have to use a bio psychosocial framework, qualitative tools, rhizomatic relations, chaos theory, and fuzzy logic".

\section{Conclusion}

So, can we truly classify, in Family Medicine, the health problems of buffaloes in easy and those of complex bison? Or does it not depend on the buffaloes or the bison, but on how much knowledge I have about of the problem? ", the doctor asked himself.

Biological and social systems are inherently complex, so it is surprising that any human disease can be said to have a single cause or cure [11]. To classify patients' problems as easy, complicated, complex and chaotic (easy and difficult) is a conventional one, which can only have pedagogical purposes: all problems are always very complex, and to characterize them in another way depends on where we arbitrarily stop our inquiry. Primary Care is not "primitive care" [7]. On the contrary, as we ascend on the scale of specialization, problems become less complex. And the deeper you dig into the problem, the more puzzles you will encounter.

\section{References}

1. Cassell EJ (1997) Doctoring. The nature of primary care medicine. Oxford University Press, New York, USA. p: 206.

2. Turabian Jl, Perez Franco B (2010) An easy or difficult case? Shapes drawn from life. Uncertainty based family medicine 36: 485-490.

3. Turabián JL, Pérez Franco B (2016) A way of helping "Mr. Minotaur" and "Ms. Ariadne" to exit from the multiple morbidity labyrinth: The "master problems". Semergen. ; 42: 38-48.

4. Turabián JL, Pérez-Franco B (2015) Ghost stories to learn family medicine. Making aware the methods to manage the uncertainty in family medicine. Editorial Académica Española, Berlin.

5. Turabián JL, Pérez-Franco B (2014) Album of models for qualitative tools in the Family Medicine decision making. Other maps to describe a country. Semergen 40: 415-24.

6. Turabián JL, Pérez Franco B (2006) Variablility is an Indicator of Good Clinical Management in Family Medicine. Aten Primaria 37: 160-166.

7. Turabián JL, Pérez Franco B (2006) The Process by Which Family Doctors Manage Uncertainty: Not Everything Is Zebras or Horses. Aten Primaria; 38: 165-167.

8. Turabian JL, Perez Franco B (2007) Framework of Competences of Family Doctors: Clinics or People? Aten Primaria; 39: 41-43.

9. Turabian JL (2009) Specific tools to manage complex consultations in general practice. BMJ 338: b1187.

10. Turabian JL (2003) Una medicina a escala humana. JANO LXV: 10.

11. Wilson T, Holt T, Greenhalgh T (2001) Complexity and clinical care. BMJ 323: 685-688. 